\title{
CARcinogen EXposure: CAREX
}

\section{Saeed Yari ${ }^{1}$, Ayda Fallah Asadi², Alireza Mosavi Jarrahi ${ }^{3}$, Mohammad Nourmohammadi ${ }^{4}$}

${ }^{1}$ School of Health Science, Shahid Beheshti University of Medical Sciences, Tehran, Iran. ${ }^{2}$ School of Nursing and Midwifery, Ghazvin University of Medical Sciences, Ghazvin, Iran. ${ }^{3}$ School of Medicine, Shahid Beheshti University of Medical Sciences, Tehran, Iran. ${ }^{4}$ Department of Occupational Health Engineering, School of Public Health, Tehran University of Medical Sciences, Tehran, Iran.

\begin{abstract}
Cancer is the second common cause of death worldwide and a significant ratio of all cancers is related to occupational and living environments. On the other side, cancer prevalence could be controlled and prevented via policies to improve occupational and living environments. However, a main challenge in prevention of occupational cancer is the lack of knowledge about the exposure rate and number of exposed persons. CAREX database, which is established by the program of Europe against cancer, provides information for the number of exposed persons based on country, carcinogen, and type of industry. CAREX is established in early years of 1990 decade by Finland Institute of Health (FIOH) in cooperation with IARC and European experts, as a tool for estimation of the burden due to occupational cancer in Europe, and shortly thereafter is expanded for use in almost 15 countries in European Union by 55 industrial groups. Several other countries have used CAREX for their countries and have provided some main progressions for the performance model. CAREX project in Canada was modeled in 2007, in an effort to develop a Canadian specific and advanced tool for assessing exposure to carcinogenic agents based on EU CAREX. In this model, not only occupational exposure, but also environmental exposure has been considered. Estimation of exposure with CAREX helps to inform primary prevention activities and to improve global occupational cancer, and its strength points are systematic nature, good coverage and ease of use, and can be used in other countries of the world.
\end{abstract}

Keywords: CAREX- Carcinogen Exposure- Occupational Cancer- Environmental Cancer- Cancer Prevention

Asian Pac J Environment and Cancer, 1 (1), 19-25

\section{Introduction}

Cancer is the second cause of death worldwide and one of the most progressive diseases in the world. In 2008, 7.6 million mortality due cancer and 12.7 million new cases of cancer are detected. And 15 million new cases are detected annually [1-2]. More than half of cancers and $63 \%$ of mortality caused by cancer is reported to occur in low and middle income countries [3]. Humans are exposed to several carcinogens through inhalation, eating, drinking and skin contact [4-5]. Since most of people work for almost two-thirds of their lives, they have many and often long-term opportunities to deal with occupational cancers, which can lead to accumulation of life-threatening exposures [3]. So that, $6-10 \%$ of cancers in USA are related to occupation [6-7]. It was found in
Submission Date: 06/26/2018 Acceptance Date:08/24/2018

\section{Corresponding Author:}

Dr. Saeed Yari

School of Health Science, Shahid Beheshti University of Medical Sciences, Tehran, Iran.

Email: SMaeedY@gmail.com 
Program (USNTP), have published lists of chemicals and carcinogen components based on new scientific researches [12]. Although, as much as these lists are valid, they are not comprehensive; as they only provide information about the evaluated materials. So that, based on estimation of National Institute for Occupational Safety and Health (NIOSH) of USA, only less than 2 percent of current chemicals have been analyzed [13]. Moreover, carcinogen chemicals are growing continuously, and/ or are transferred from one group to the other, as our understanding of their carcinogenesis improves [14]. On the other side, cancer prevalence could be controlled and prevented via policies to improve occupational and living environments [15]. Prevention is more effective and economic than convincing thousands of people to change their personal behaviors [16-17], and exposure to environmental and occupational cancers is always preventable [3]. Primary prevention includes decreasing or removing carcinogen exposure; Such as deletion of aromatic amines and reduction of bladder cancer caused by it, among color industry employees [18]. Actions for reducing or eliminating exposures will help reduce the risk of cancer in the future [10-19]. However, a main challenge in prevention of occupational cancer is lack of knowledge about the exposure rate and number of exposed persons [20]. Information of occupational or environmental exposure of people with cancer, work history, etc. are rarely systematically collected, except in special cases [21]. So, lack of information about the industrial extent and distribution of occupational exposure to carcinogens in most of countries makes the evaluation and surveillance of risk difficult [22-23]. Estimates show that at least one third of cancers can be prevented based on current data [24]. For filling gaps in the understanding of causes of cancer and carcinogen exposure, governmental and academic researchers have used epidemiological studies to relate occupational and environmental exposure to cancer [21]. In Canada, the best ongoing surveillance program is the National Dose Registry, which monitors exposure to known carcinogens such as ionizing radiation [25]. In Europe, Finland has a system that shows evidence of exposure of employee to carcinogens [20]. This system was established to prevent the development of occupational cancers [26]. Today, there are advanced methods that can be used to evaluate the level of diseases due to specific occupational exposure, and/or to assess all occupational exposure to carcinogenic agents with the incidence of cancer [27]. The Carcinogenesis Prevention Database is used as the basis for estimating the Risk Exposure Period (REP) in different sections of the industry, based on changes in staff levels and turns [28-29]. CAREX is an international information system related to known and suspected carcinogenesis exposure [30]. The CAREX database, which has been developed with the support of the European Union against cancer program, provides information about the number of exposed persons by country, carcinogen, and industry type $[20,31]$. Although this database has information about occupational cancers, this information is known as the "top of the iceberg" [21]. However, Policy makers in a number of countries are trying to extent public policies and cancer prevention programs to develop occupational matrixes and cancer exposure-related information systems such as CAREX, which for Finland (Finnish Institute for Health Professionals 2010) it has been pioneered and has other countries such as Canada, Costa Rica and EU countries has used it [20, 32-33].

\section{EU CAREX}

Evaluation of accessible manuscripts such as monographs of International Cancer Research Agency shows that often there is no direct estimation about number of carcinogen exposure employee. So, it is obvious that most of estimations should be indirectly obtained by professional judgment, based on published and unpublished information. For this purpose, a group of international experts was invited to a meeting in March 1995 to develop a plan for estimating carcinogens exposure. After primary meeting, the first version of the CAREX system was developed by the Finnish Institute of Health (FIOH) to help the estimation [26-31]. CAREX was tested and in another meeting, experts were extended it. As the effect of nationality information in the assessing process was required, experts from other countries participated in this project. Scientists have significantly helped planning, designing, collecting data, and assessing exposure in the CAREX system [31-34]. To facilitate the estimation and documentation of the basis of estimates, the system was designed and built on the basis of Microsoft Access database [35]. Priority was to use national estimations of carcinogen effect, however, low accessibility to this data caused to the approach that most of values will be indirectly obtained of staff information, and exposure estimation of two reference countries (Finland and USA) [36]. This included information for 139 carcinogen agents (which were estimated in 1995, the February by IARC), including all group 1 agents (certain carcinogens), all group 2A agents (probable carcinogens), and selected agents of group 2B (possible carcinogens such as inorganic Lead, Glass, Styrene, Methylene Chloride, Cobalt, Pentachlorophenol, Carbon tetrachloride) [31, 36-37]. Moreover, Ionizing radiation is also included, because although it has not been evaluated by the IARC, there are adequate evidences of carcinogens in humans [31]. Also, some of the groups 1 or $2 \mathrm{~A}$ agents are polycyclic aromatic hydrocarbons (PAHs), or a mixture of them, which are integrated and investigated under this heading. The cause of this revise was that PAHs almost always are found in the occupational environments as a complicated composite, and PAH exposure is undetectable. However, tobacco smoke and diesel exhaust (while are known as complicated composites of PAH) are assessed separately [31-38]. Exposure routes in CAREX are exposure ways (inhalation, skin, or both) and the non-professional background level that is used as the minimum occupational exposure [20-31]. Calculation of the first estimations was based on SUTKEA, FINJEM, ASA and US NOES exposure data[39-40]. One of the most essential ASA information that has been preserved by FIOH since 1979, and is based on annual announcements of staff exposures 
and the use of carcinogens. ASA announcement is required and covers all Salaried employees in Finland. However, ASA coverage is incomplete for several exposures, as in some cases exposures are not reported or employers are unaware of exposure or ignore their duty of announcement $[31,41]$. Also, SUTKEA estimation was not used and if none of these two system o not provide any estimation, other current sources were used as the basis for evaluation. The main source of data from Finland is the report of a comprehensive estimate (SUTKEA project) performed by the FIOH in the late 1980s and early 1990s. SUTKEA is a summary of the exposure information and FIOH experience about the situation in Finland. Most exposure information for SUTKEA collected in CAREX is given as background data to indicate the level of exposure to various tasks [26, 31-42]. As measurements are done in detail for matching purposes, they can be linearly extended to all workers in the exposed industries [20-31]. The main criterion for occupational exposure in Finland was that the annual dose at work was higher than the non-professional dose [31]. This also was the proposed criteria for exposure evaluation in CAREX for other countries [42]. Eventually, CAREX was established in early years of 1990 decade by Finland Institute of Health $(\mathrm{FIOH})$ in cooperation with IARC and European experts, as a tool for estimation of the burden due to occupational cancer in Europe. Shortly thereafter, it was expanded for use in almost 15 countries in European Union (exposure information from 1990 to 1993), and in 4 out of 10 countries in European Union in 2004 (exposure data from 1997) by 55 industrial groups of United Nations Organization 9ISIC Revision 2)[31, 37, 43]. The exposure to these carcinogenic agents in the 1990-1993 period was calculated for twelve countries in the European Union [43]. CAREX includes information about the number of industrial workers, exposure summarized data, number of staffs, description of carcinogen exposure, description of estimation methods, and bibliographic references [26, 44]. This database provides descriptive reports and data tables on carcinogenic agents since the early 1990s, which there could be small differences between reports and tables, as some of values of staffs, and/or exposure estimations which are entered in the tables, will be updated

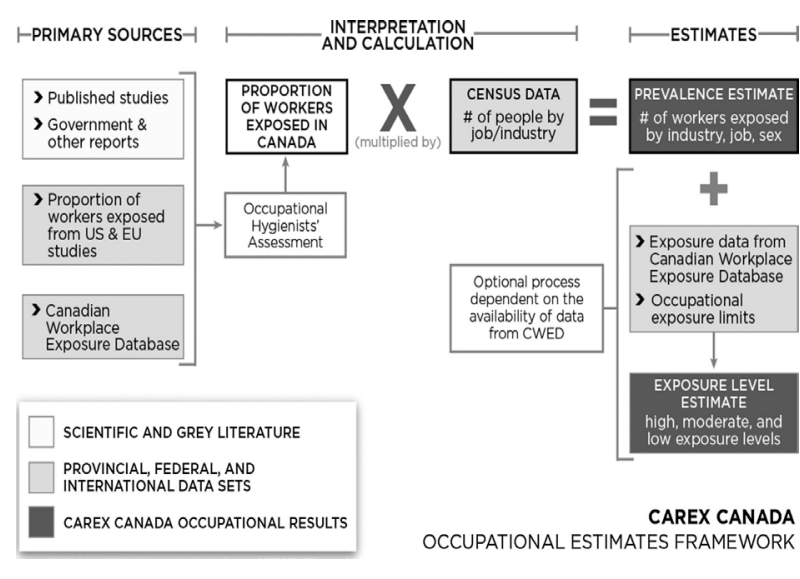

Figure 1. Estimation Algorithm of Occupational Exposure for Known and Suspicious Carcinogens after publication of the report [45]. Finnish Information System on Occupational Exposure (FINJEM; Finnish job-exposure matrix), is developed in 1990 decade to assess occupational history and quantitative estimations of carcinogen agent exposure. This is a Job Exposure Matrix (JEM), which contains estimations of the specific period of time of exposure to occupational factors and periods, which has assessed more than 300 jobs over time[4, 4648]. According to the estimations, between years 1990 to 1993 , around 500,000 workers ( $24 \%$ of workers) in Finland, had covered CAREX agents exposure [31]. Regarding the importance of CAREX in prevention of occupational cancer, several other countries worldwide have used the original system for their countries, and have made several major improvements in the model. A clear example of this, is CAREX Costa Rica (entitled TICAREX), which also considered exposure to pesticides for the first time, and considered sex as a determining property in occupational exposure [49]. In Canada, this system was more widely considered, where hundreds of exposed industries, jobs, sex, and geographical areas were assessed [4-33]. Moreover, a completely new system was added to consider the effects of environmental carcinogens. The Canadian team in cooperation with Panama's World Health Organization and its other partners has expanded the use of improved CAREX to other countries, especially low-income and middle-income countries, whose research capacity and new data structuring may be difficult. After 25 years, CAREX is still needs developing and improving [35]. The first estimations were not directly valid for other countries, as the industrial structure, consumption pattern of factors, and other temporary factors may differ significantly in different countries. Hence, the national experts corrected the first estimations and recorded the alterations in the database to be applicable in other countries as well [31]. So that the CAREX approach was later established in Estonia, Latvia, the Czech Republic and Lithuania [50].

\section{CAREX Canada}

Annually, 77900 to 112000 new cases of occupational cancer and 2381 to 6010 mortality due to the occupational diseases are reported [51]. Canadian CAREX project was started in 2007, and in an effort to develop a Canadian specific and advanced tool for assessing exposure to occupational carcinogenic agents. It was modeled after EU CAREX and designed to attract strength points of this system. Canadian CAREX also includes components that are focused on environmental exposure [4-10]. The aim of the occupational section of Canadian CAREX is to estimate number of Canadian staff which is at risk of known and suspicious cancers, and if there is the possibility, determines their prevalence rate [4]. Canadian CAREX is the Canadian version of database including data of British Columbia and Ontario. Early estimations are developed in Ontario, and are added to the Canadian CAREX [36]. Introduction of hundreds of industrial exposures was more than presented resources for Canadian CAREX; however, exact estimation of staff was added to the database. ISIC-2 groups are converted to the industrial 
survey groups [4-36]. Information of Ontario survey section entered CAREX database in 2001 to estimate number of staff who are at the potential risk of carcinogenic exposure. Primary data presented in the Canadian CAREX was based on the proportion of staffs in Finland and USA [4-52]. Canadian CAREX instruction in that time was to estimate prevalence and rate of exposure to the important occupational cancers in Canada, and transferring research data to the scientific society, policy makers, regulators, and general population. For performing these missions, Canadian CAREX in 2007 developed rules for prioritizing occupational cancers, and for estimation purpose. Afterwards, in 2015, another program was introduced to determine preventive actions in the case of cancer prevention in Canada [52-53]. The aim of Canadian CAREX project was to detect number of Canadian staffs that are exposed by carcinogenic agents in work place and environment. While the occupational aspect of the project was mainly based on the EU CAREX project, Canadian CAREX started as a result of some creative actions based on the Finnish occupational exposures matrix (FINJEM), Costa Rica, and other big projects which were presented at that time [43-46]. Canadian CAREX wanted to strengthen the main model of CAREX using two methods: first, exposure rate prevalence according to the both industry (328 subgroups) and occupation (520 subgroups), has been evaluated in a more advanced manner than previous projects, which was for better evaluation of exposure and exposure rate for targeting the preventive efforts. Second, if there is the possibility, exposure rate calculated using cutting points based on the occupational limitations in the three low, middle, and high groups, respectively. For facilitating this classification, occupational exposure database was developed in Canada work conditions, based on several hundred thousands of measurements in cooperation with monitoring organizations. These progressions made CAREX Canada a very effective tool for both prevention and development of occupational exposure matrix of epidemiological programs. This project also has a systematic method for detection of current gaps in the information [4, 43, 54-55]. Before late 1990 decade, Canada didn't have central information related to the carcinogen agents. For solving this problem, in 2003, a group of researchers from British Columbia University worked on a project to perform main Finland model for estimation of carcinogenic agents in work place at BC [28]. Moreover, in May of 2004, Canada health has done programs to develop a cooperative national environmental health center in British Columbia, one of the six national centers specified to the general health subjects. This center was assessing subjects in the occupational and environmental health field including chemical agents and climate quality, and had an important role in the assessment of national health [21]. Occupational Cancer Research Center (OCRC), has established in early months of 2009, to solve this problem in Ontario. The aim of this center was to detect carcinogenic agents, and preventing, and eventually removing their exposure in the work place, by monitoring and scientific researches, and intervention and distribution of knowledge [56].
OCRC is provided by the Cancer Center of Ontario (CCO). Ontario section of Canadian Cancer society (CCS), is a private organization, and Workplace and Safety Insurance Board (WSIB) is the Ontario's Workers Compensation Institute. This center has developed in cooperation with steel workers United. WSIB also works with some other research centers that are focused on the other subjects of occupational health, such as Institute of Work and Health (IWH), Center of Research on Occupational Disease (CREOD), and Center of Research on the Prevention of Musculoskeletal Disorders (CRE-MSD). Several exposure priorities mentioned by OCRC, are also research priorities determined by National Occupational Research of America (NORA) program, including the need for better detection of suspicious cancers (such as chemicals), detection of carcinogens (such as nano-material), continuous monitoring of known occupational carcinogens (such as asbestos) [44, 56-59]. This database advanced national monitoring of cancer centers are maintained by Health Canada [60]. Unique progressions in the Canadian project include occasional exposure via industry (based on industrial classification system of America or NAICS, version 2002), and occupation (based on national occupational - survey classifications, version 2006), states or kingdom, and gender [4]. In Canada, evaluation of exposure of states is important, as preservation of workplace is highly managed in the states level, and exposure estimation in this level allows states to determine their priorities. This kind of monitoring for information of carcinogens exposure could be used for detection of high-risk groups. These estimations expanded in that time, and CWED containing almost 100000 exposure to known and suspicious carcinogenic agents, 1981 to 2004 were measured for monitoring purposes in two big states of Canada. CWED has expanded continuously, as other states of Canada helped in providing information, and in the time of writing, includes 460000 exposure actions (carcinogenic and non-carcinogenic) [60-61]. Other resources were EU CAREX project, published manuscript about exposure to the occupational carcinogenic agents, and governmental reports. For estimation of UVR levels, reports of International Commission of Ultraviolet Radiation Protection reports were used (ICNIRP). Totally, CAREX Canada performs occupational estimations for 44 known carcinogenic and occupational suspicious agents, and 18 cases of probable carcinogenic agents. The most common exposure in Canada was work shifts (1.9 million exposures), the sun UV radiation in workers of open places (1.5 million exposures), and Exhaust diesel engines, and benzene. CAREX Canada has provided profiles and estimations of occupational and environmental harms for some of known probable carcinogenic agents, based on Figure 1 [4]. Exact information regarding data and methods is accessible for all estimations and profiles. These profiles and estimations could help scientists, policy makers, and other experts of this field to prevent cancer and detect priorities, and to target societies or workplaces for research and/or intervention actions [51]. As an example, this information shows us that the number of new cases in Canada is increasing, and in the next 20 
years, the total number of cancer cases will increase by $60 \%$ [62]. In the field of environment, federal government and academic researchers focused their efforts to assess the correlation between environmental factors and cancer, and a national database developed in this case [21]. Also between 2012-18, CAREX Canada will undertake a knowledge mobilization program to make CAREX information available and accessible to Canada's cancer prevention and policy arena[28]. These progressions can be used in other countries with data related to the staffs.

In conclusion, Prioritizing and scoring occupational cancers for different purposes, such as research, distribution of resources in different judicial levels, calculation of occupational cancer burden and programing of CAREX projects in different countries is necessary [53]. Estimation of exposure using CAREX is for informing about primary prevention activities and improving global occupational cancer [43]. Composition of CAREX and current measurement databases, provides the possibility for estimation of number of carcinogen exposed workers. Some other effective measurement databases are NEDB, COLCHIC, MEGA, or research databases such as ExpoSYN. For improving CAREX efficiency for estimation of global disease burden due to occupational carcinogenic agents, it is required to determine number of exposed staffs, and real levels of exposure, regarding time changes and global economic and area differences (economy of high-income countries in comparison to economy of low-income countries) [55]. Ignoring this big problem, we should consider that we need information of all industries only for limited number of studied materials (such as asbestos, Crystalline Silica, Smoke Pile, Wood Dust) $[30,42,55,63]$. Even these data are not extracted of developing countries. CAREX is designed for Promote prevention by raising awareness and targeting high risk people. CAREX is designed as a system that can be used in other countries and its usage in international level could be expanded [64]. Low budget is provided for occupational and environmental researches. It has been estimated that for monitoring cancer, essential research institutes specified 90 to 95 percent of their helps to the treatment and treatment researches, and only 5 to 10 percent of cancer causes and preventing carcinogenic agents. Information of environmental and occupational carcinogenic exposure, is collected only for specific assessments. There is deficiency in the current information of carcinogenic occupational exposure. Also, there is a significant gap in monitoring and lack of knowledge about environmental carcinogenic agents [4, 10, 21-65]. Despite this significant success in detection of human cancers from occupational studies, our efforts for detection and determination of carcinogens agents may be decreased during last decades and needs new research creativity for detection of unknown carcinogenic agents [59-66]. In summary, strength points of CAREX are systematic nature, good coverage, and ease of use. Although there are several methods for improving validation and making the process easier, and current methods are from the best accessible methods, validity of estimation is still worrying and had inner unreliability. Probable error resources are difference in description of occupational exposure, removing specific patterns of country exposure, differences in validity of referred data, problems in classification of industries, and problems in estimation of multiple effects. However, several of these problems are related to the data complex of Finland, as Finland is one of the reference countries and number of persons at exposure risk was estimated directly by national experts. Estimation of Finland has previously lost its validity as they belong to the 1990 to 1993 period of time that after that status of some of exposure has significantly changed. For example, in 1995 smoking in workplace become banned in Finland and its exposure significantly decreased. Another example is ethylene die bromide presented in leaded gasoline that this type of gasoline is only used in 1990 to 1993 [20-31]. For using occupational carcinogenic exposure risk reduction strategies, and distribution of current resources, high quality information is required based on the scientific documents. With this aim, institute of occupational health and safety in Catalonia, has developed the map for prevalence of current cancers in Catalonia (CAREXCAT), based on CAREX system [67-68]. Results of CAREX programs are used in LAC of Costa Rica, Nicaragua, Panama, Guyana, Colombia, Peru, and Chile, which showed that CAREX common method could be used easily in different countries [43-46]. Another method for assessing national carcinogenic agent's exposure recently has been used in Australia [4].

\section{References}

1. Ferlay J, Shin HR, Bray F, Forman D, Mathers C, Parkin DM. Estimates of worldwide burden of cancer in 2008: GLOBOCAN 2008. International journal of cancer. 2010;127(12):2893-917.

2. Fitzmaurice C, Dicker D, Pain A, Hamavid H, Moradi-Lakeh M, MacIntyre MF, et al. The global burden of cancer 2013. JAMA oncology. 2015;1(4):505-27.

3. Espina C, Porta M, Schüz J, Aguado IH, Percival RV, Dora C, et al. Environmental and occupational interventions for primary prevention of cancer: a cross-sectorial policy framework. Environmental health perspectives. 2013;121(4):420.

4. Peters CE, Calvin BG, Hall AL, Davies HW, Demers PA. CAREX Canada: an enhanced model for assessing occupational carcinogen exposure. Occup Environ Med. 2014:oemed-2014-102286.

5. Normohammadi M, Kakooei H, Omidi L, Yari S, Alimi R. Risk assessment of exposure to silica dust in building demolition sites. Safety and health at work. 2016;7(3):251-5.

6. Lynge E, Anttila A, Hemminki K. Organic solvents and cancer. Cancer Causes \& Control. 1997;8(3):406-19.

7. Yari S. Inherent safety design in compose of urban gas station. Safety Promotion and Injury Prevention. 2015;3(2):135-40.

8. WHO J. Global health risks: mortality and burden of disease attributabbl to selected major risk. Geneva: WHO; 2009.

9. Prüss-Üstün A, Corvalán C. How much disease burden can be prevented by environmental interventions? Epidemiology. 2007;18(1):167-78.

10. Setton E, Hystad P, Poplawski K, Cheasley R, CervantesLarios A, Keller CP, et al. Risk-based indicators of Canadians' exposures to environmental carcinogens. Environmental Health. 2013;12(1):15. 
11. IARC. AGENTS CLASSIFIED BY THE IARC MONOGRAPHS, VOLUMES 1-122 2018 [cited 1-122]. Available from: https://monographs.iarc.fr/agents-classifiedby-the-iarc/.

12. Program TNT. Tenth Edition of the Report on Carcinogens.

13. Health NIfOSa. Occupational Cancer. Available from: http:// www.cdc.gov/niosh/topics/cancer/.

14. Release IP. IARC CLASSIFIES FORMALDEHYDE AS CARCINOGENIC TO HUMANS 2004 [153]. Available from: http://www.iarc.fr/pageroot/PRERELEASES/pr153a. html.

15. Prüss-Üstün A, Corvalán C. Preventing disease through healthy environments. Towards an estimate of the environmental burden of disease Geneva: World Health Organization. 2006.

16. Doyle Y, Furey A, Flowers J. Sick individuals and sick populations: 20 years later. Journal of Epidemiology \& Community Health. 2006;60(5):396-8.

17. Asaria P, Chisholm D, Mathers C, Ezzati M, Beaglehole R. Chronic disease prevention: health effects and financial costs of strategies to reduce salt intake and control tobacco use. The Lancet. 2007;370(9604):2044-53.

18. Tomatis L. Cancer: causes occurence and control. IARC scientific publications. 1990

19. Clapp RW, Jacobs MM, Loechler EL. Environmental and occupational causes of cancer: new evidence 2005-2007. Reviews on environmental health. 2008;23(1):1-38.

20. Kauppinen T, Toikkanen J, Pedersen D, Young R, Ahrens $\mathrm{W}$, Boffetta $\mathrm{P}$, et al. Occupational exposure to carcinogens in the European Union. Occupational and environmental medicine. 2000;57(1):10-8.

21. Wordsworth A. Prevention of Occupational and Environmental Cancers in Canada. National Committee on Environmental and Occupational Exposures. 2006:107.

22. Yari S, Fallah AA, Varmazyar S. Assessment of semiquantitative health risks of exposure to harmful chemical agents in the context of carcinogenesis in the latex glove manufacturing industry. Asian Pacific journal of cancer prevention: APJCP. 2015;17:S3.

23. Yari S. Assessment of potential risk by the failure mode and effects analysis in an air conditioning equipment manufacturing company. Safety Promotion and Injury Prevention. 2017;5(2):89-96.

24. Danaei G, Vander Hoorn S, Lopez AD, Murray CJ, Ezzati $\mathrm{M}$, group CRAc. Causes of cancer in the world: comparative risk assessment of nine behavioural and environmental risk factors. The Lancet. 2005;366(9499):1784-93.

25. Ashmore J, Krewski D, Zielinski J, Jiang H, Semenciw R, Band P. First analysis of mortality and occupational radiation exposure based on the National Dose Registry of Canada. American journal of epidemiology. 1998;148(6):564-74.

26. Kauppinen T. Finnish occupational exposure databases. Applied occupational and environmental hygiene. 2001;16(2):154-8.

27. Kraut A. Estimates of the extent of morbidity and mortality due to occupational diseases in Canada. American journal of industrial medicine. 1994;25(2):267-78

28. carexcanada. What is CAREX? 2018. Available from: https:// www.carexcanada.ca/en/aboutus/.

29. Rushton L, Brown T, Cherrie L, Fortunato L, Van Tongeren $\mathrm{M}$, Hutchings S. How much does benzene contribute to the overall burden of cancer due to occupation? 2010.

30. Mirabelli D. Estimated number of workers exposed to carcinogens in Italy, within the context of the European study CAREX. Epidemiologia e prevenzione. 1999;23(4):346-59.

31. Heikkilä P, Kauppinen T. Occupational exposure to carcinogens in Finland. American journal of industrial medicine. 1992;21(4):467-80.

32. Partanen T, Chaves J, Wesseling C, Chaverri F, Monge $\mathrm{P}$, Ruepert $\mathrm{C}$, et al. Workplace carcinogen and pesticide exposures in Costa Rica. International journal of occupational and environmental health. 2003;9(2):104-11.

33. Ezzati M, Lopez AD, Rodgers A, Vander Hoorn S, Murray CJ, Group CRAC. Selected major risk factors and global and regional burden of disease. The Lancet. 2002;360(9343):1347-60.

34. Rushton L, Bagga S, Bevan R, Brown T, Cherrie J, Holmes $\mathrm{P}$, et al. Occupation and cancer in Britain. British Journal of Cancer. 2010;102(9):1428.

35. Peters C, Pahwa M, Demers P. 0284 Carex: an occupational exposure surveillance system overview. BMJ Publishing Group Ltd; 2017.

36. Angeles J. Estimating the burden of occupational bladder cancer in Ontario using the CAREX Canada database 2008.

37. Leem J-H, Kim H-C, Ryu J-S, Won JU, Moon JD, Kim Y-C, et al. Occupational lung cancer surveillance in South Korea, 2006-2009. Safety and health at work. 2010;1(2):134-9.

38. Armstrong BG, Gibbs G. Exposure-response relationship between lung cancer and polycyclic aromatic hydrocarbons (PAHs): estimates from a large aluminium smelter cohort. Occupational and environmental medicine. 2009.

39. Pajarskiene B, Kauppinen T. Occupational exposure to carcinogens in Lithuania in 1997. Helsinki: Finnish Institute of Occupational Health. 2000.

40. Mirabelli D. Stima del numero di lavoratori esposti a cancerogeni in Italia, nel contesto dello studio europeo CAREX. Epid Prev. 1999;23(4):346-59.

41. Ladou J, Teitelbaum DT, Egilman DS, Frank AL, Kramer SN, Huff J. American College of Occupational and Environmental Medicine (ACOEM): a professional association in service to industry. International journal of occupational and environmental health. 2007;13(4):404-26.

42. Mirabelli D, Kauppinen T. Occupational exposures to carcinogens in Italy: an update of CAREX database. International journal of occupational and environmental health. 2005;11(1):53-63.

43. Guzman JR, Demers PA, Pahwa M, Peters CE, Calvin BG. S10-3 Establishing national carcinogen exposure (CAREX) programs in latin america and the caribbean: achievements and future directions. BMJ Publishing Group Ltd; 2016.

44. Lippel K, Eakin J, Holness L, Howse D. MONDAY, OCTOBER 20, 2014.

45. health fioo. International Information System on Occupational Exposure to Carcinogens 2018. Available from: https://www. ttl.fi/en/carex/.

46. Demers PA, Peters CE, Davies HW, MCalvin BG, Hall $\mathrm{AL}, \mathrm{Kim}$ J, et al. S10-2 Carex canada: innovations and applications. BMJ Publishing Group Ltd; 2016.

47. Takala J. Eliminating occupational cancer in Europe and globally. 2015.

48. Kauppinen T, Uuksulainen S, Saalo A, Mäkinen I, Pukkala E. Use of the Finnish Information System on Occupational Exposure (FINJEM) in epidemiologic, surveillance, and other applications. Annals of occupational hygiene. 2014;58(3):380-96.

49. Lißner TL, Kooperationsstelle Hamburg I, Kuhl K. Europe Direct-palvelu auttaa sinua löytämään vastaukset EU: hun liittyviin kysymyksiisi. 2014.

50. Kauppinen T, Toikkanen J, Pukkala E. From cross-tabulations to multipurpose exposure information systems: a new jobexposure matrix. American journal of industrial medicine. 1998;33(4):409-17.

51. Driscoll T, Steenland K, Nelson DI, Prüss-Üstün A, Campbell-Lendrum DH, Corvalán CF, et al. Occupational 
carcinogens: assessing the environmental burden of disease at national and local levels. 2004.

52. Demers PA, Nicol A-M. Development of a Provincial Exposure Database for Manitoba. 2014.

53. Peters CE, Palmer AL, Telfer J, Calvin BG, Hall AL, Davies HW, et al. Priority Setting for Occupational Cancer Prevention. Safety and health at work. 2018;9(2):133-9.

54. Kim J, Labrèche F, Song C, Peters CE, Davies HW, Lavoué J, et al. O39-3 Accounting for exposure to multiple carcinogens in occupational cancer burden estimation. BMJ Publishing Group Ltd; 2016.

55. Kromhout H. S10-4 Linking carex with exposure measurement databases. BMJ Publishing Group Ltd; 2016.

56. Tompa E, Kalcevich C, McLeod C, Lebeau M, Song C, McLeod K, et al. The economic burden of lung cancer and mesothelioma due to occupational and paraoccupational asbestos exposure. Occup Environ Med. 2017:oemed-2016-104173.

57. Pasetto R, Terracini B, Marsili D, Comba P. Occupational burden of asbestos-related cancer in Argentina, Brazil, Colombia, and Mexico. Annals of global health. 2014;80(4):263-8.

58. Hohenadel K, Pichora E, Marrett L, Bukvic D, Brown J, Harris S, et al. ARCHIVED-Chronic Diseases and Injuries in Canada.

59. Hohenadel K, Pichora E, Marrett L, Bukvic D, Brown $\mathrm{J}$, Harris S, et al. Priority issues in occupational cancer research: Ontario stakeholder perspectives. advocate. 2011;21:11.9.

60.J ohnson KC. National Enhanced Cancer Surveillance System: a federal-provincial collaboration to examine environmental cancer risks [Status report]. Chronic Diseases and Injuries in Canada. 2000;21(1):34.

61. Hall AL, Peters CE, Demers PA, Davies HW. Exposed! Or not? The diminishing record of workplace exposure in Canada. Can J Public Health. 2014;105(3):214-7.

62. Mullan N, Ferguson C, Paech D, Australia W. Environmental Health Surveillance. 2008.

63. Kauppinen T, Pajarskiene B, Podniece Z, Rjazanov V, Smerhovsky Z, Veidebaum T, et al. Occupational exposure to carcinogens in Estonia, Latvia, Lithuania and the Czech Republic in 1997. Scandinavian journal of work, environment \& health. 2001:343-5.

64. Demers PA, Peters C, Pahwa M, MacLeod J, Kim J. 0452 Uses of carex systems for individual countries and international contexts. BMJ Publishing Group Ltd; 2017.

65. González CA, Agudo A. Occupational cancer in Spain. Environmental Health Perspectives. 1999;107(Suppl 2):273.

66. Blair A, Marrett L, Freeman LB, editors. Occupational cancer in developed countries. Environmental Health; 2011: BioMed Central.

67. Martín-Bustamante M, Molinero-Ruiz E. S10-1 Occupational exposure to carcinogens in catalonia: carex-cat. knowledge into action. BMJ Publishing Group Ltd; 2016.

68. Julià M, Vives A, Tarafa G, Benach J. S09-4 The precarization of the spanish labour market and its impact on mental health. BMJ Publishing Group Ltd; 2016.

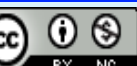

This work is licensed under a Creative Commons AttributionNon Commercial 4.0 International License. 